\title{
All About That Base
}

Because you know I'm all about that base

'Bout that base, no acid

I'm all about that base 'Bout that base, no acid

I'm all about that base 'Bout that base, no acid

I'm all about that base 'Bout that base

Yeah, it's pretty clear, that paper's old

But we ain't got no money, money so what we supposed to do?

'Cause we got that past, past that all the people want

All the old stats and all the old figures

We see those digital plans

They get all the attention

We got to get those scanners

And learn to use Photoshop

Convert to TIFF, TIFF, just make 'em bigger

'Cause everyone wants access

But no one wants to pay

Yeah my ACA taught me the right way to preserve

They said: let More Product Less Process be your guide

We will try to digitize all those technical manuals,

But we will have to get all those rusted fasteners right off

Because you know I'm all about that base

'Bout that base, no acid

I'm all about that base 'Bout that base, no acid

I'm all about that base 'Bout that base, no acid

I'm all about that base 'Bout that base

Hey!

We're bringing history back

Go ahead and tell the IT department that, Hey

No, we know we need your help

So don't put us all on hold

Or we will take up all your space 
Yeah my ACA taught me the right way to preserve

They said: let More Product Less Process be your guide

We will try to digitize all those technical manuals

But we will have to get all those rusted fasteners right off

Because you know I'm all about that base

'Bout that base, no acid

I'm all about that base 'Bout that base, no acid

I'm all about that base 'Bout that base, no acid

I'm all about that base 'Bout that base

Hey!

Because you know I'm all about that base

'Bout that base, no acid

I'm all about that base 'Bout that base, no acid

I'm all about that base 'Bout that base, no acid

I'm all about that base 'Bout that base

Hey!

Because you know I'm all about that base

'Bout that base, no acid

I'm all about that base 'Bout that base, no acid

I'm all about that base 'Bout that base, no acid

I'm all about that base 'Bout that base

Hey, hey, ooh

We know you like this base

Parody of Meghan Trainor's "All About That Bass" 